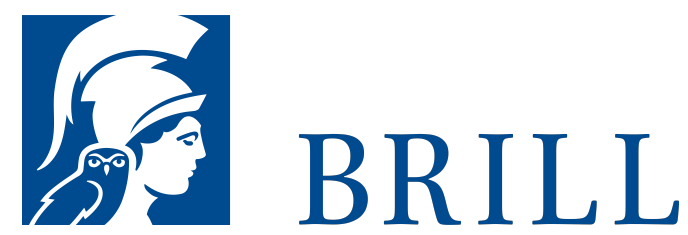

\title{
Militärische Effektivität im Ersten Weltkrieg
}

Die 11. Bayerische Infanteriedivision 1915-1918

Author: Christian Stachelbeck

Eine repräsentative Fallstudie über die Herausforderungen des industrialisierten Krieges und das Musterbeispiel einer modernen integrativen Operationsgeschichte.

Im Mittelpunkt steht das Bindeglied zwischen den höheren Entscheidungsinstanzen des Heeres und der Ebene des »kleinen Mannes «, die bislang zu wenig beachtete mittlere Führung. Der Autor fragt nach ihrer Lernfähigkeit, nach ihrer Bedeutung für taktische Innovationsprozesse wie auch für die Aufrechterhaltung und Mobilisierung der Kampfmotivation der Soldaten. Seine Ergebnisse relativieren die in vielen angloamerikanischen Studien gerühmte außergewöhnliche Leistungsfähigkeit des deutschen Heeres ebenso wie die in Deutschland oft noch verbreitete Auffassung von der Innovationsunfähigkeit der Armee.

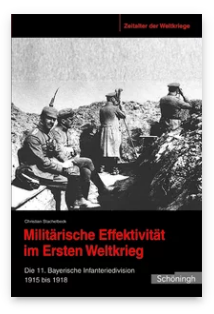

Pages: $\mathrm{X}+428$

Seiten, $5 \mathrm{~s} / \mathrm{w}$

Abb., 9 s/w Tab.

Language:

German

Subjects: Early

Modern History, History

Publisher: Brill | Schöningh

Series:

Zeitalter der

Weltkriege,

Volume: 6

Hardback

Publication date: 15 Sep 2010

ISBN: 978-3506-76980-0 List price USD $\$ 68.00$ 
For more information see brill.com

Order information: Order online at brill.com +44330 333 0049 | customerservices@brill.com Submission information: brill.com/authors

Titles published by Brill | Fink, Brill | mentis or Brill | Schöningh: +49(o)715413279216| brill@brocom.de 